\title{
9 Multi-stakeholder partnerships in fragile political contexts \\ Experiences from the Palestinian \\ water and waste sector
}

Irna van der Molen and Nora Stel

\subsection{Introduction}

The concept of multi-stakeholder partnerships (MSPs) is used as both an analytical tool and a policy prescription - often at the same time. On the one hand, a vast academic literature is dedicated to MSPs, drawing on the theoretical fields of governance, networks and management (Noor, 2010). ${ }^{1}$ On the other hand, the MSP notion has emerged from development practitioners' and policymakers' conceptions of dialogue and partnership.

We define MSPs as cooperation between different stakeholders that have an interest in a problem and together engage in a process of dialogue and cooperative action to address this problem (Vermeulen et al., 2008, p. 97; Hemmati, 2002, p. 2). These 'different stakeholders' are often conceived as coming from the private, public and civil sectors. Thus, MSPs can be seen as extended versions of, or related to, public-private partnerships (PPPs), which are defined as 'arrangements whereby private parties participate in, or provide support for, the provision of infrastructure, resulting in a contract for a private entity to deliver public infrastructure-based service' (Grimsey and Lewis, 2004 cited in Multipart, 2008, p. 43).

The common ground for an interest in MSPs, among development practitioners and policymakers, can be found across the processes of interaction and governance (Noor, 2010). As Nuijten eloquently states: 'the MSP concept is buttressed by a belief in the power of dialogue and consensusbuilding in breaking down institutional and power barriers, and the ability of people at the local level to manage local resources' (Nuijten, 2004, p. 116 , original emphasis). The leading international donors and policymaking institutions propagate this belief in MSPs in water management in general, and in the water supply, sanitation and hygiene (WASH) sector in particular.

For example, the United Kingdom Department for International Development (DfID, 2011, p. 41) welcomes MSPs as a 'promising mechanism towards building cooperative water management' and calls the water crisis a 'crisis of governance' (Plummer and Slaymaker, 2007). The United Nations sees multi-stakeholder governance as a pillar of WASH policy (United Nations Development Programme, 2004). The Organisation for 
Economic Co-operation and Development (OECD), too, considers partnerships and 'multi-stakeholder dialogue' as the solution for lacking state capacity and political will (2008, p. 34, 2012, p. 19).

Motivations for MSP dissemination invariably - either implicitly or explicitly - refer to the ability of MSPs to operationalize integrated water resource management, good governance and stakeholder participation, which are among the key concepts that dominate the debates on the management of water and waste over the last decades (see also Chapter 2). In this sense, the MSP concept is a rather complex one that contains elements of all three panaceas or perceived universal remedies that are described in Chapter 2. MSPs are perceived as a way to enhance equity, accountability, democracy, transparency, participation and integration (Noor, 2010, p. 36). MSPs are praised for their ability to link top-down and bottom-up; indigenous and foreign; and state and non-state approaches and are assumed to make service delivery more inclusive, participatory and effective (Hofmann, 2009, cited in Noor, 2010, p. 36; van Tongeren and van Empel, 2007, p. 14).

With the adoption of Agenda 21, specifically its section on 'strengthening the role of major groups', at the Earth Summit in Rio de Janeiro, partnerships and MSPs were introduced as new forms of governance. The importance of partnerships was reiterated at the Johannesburg Summit in 2002 (Multipart, 2008). Recognizing that neither the state, nor the market, nor communities seem to be able to manage water on their own, MSPs were coupled with integrated water resource management (De Boer and Pfisterer, 2009). The emergence of MSPs can therefore also be perceived as part of a process of diversification of governance modalities (Sørensen and Torfing, 2005, p. 199; Pierre and Peters, 2000).

In this chapter, we discuss both the transfer of the MSP concept in the water and the waste sector, and the underlying assumption that this governance concept is - with some adjustments - applicable and effective also in fragile contexts that are characterized by conflict, political instability and institutional multiplicity.

Based on fieldwork in the Palestinian Territories, we suggest that multistakeholder governance of water, sanitation and waste management is a requirement for successful service provision in these sectors because of the fragility of the governance context. This is already widely recognized and applied by relevant Palestinian stakeholders and policymakers. As such, it is misguided to assume that MSPs are an entirely new construct, a tool that needs to be introduced to 'modernize' water management in developing countries and/or fragile situations. Our cases show that MSPs are not a new concept introduced by donor organizations, but emerge both with and without donor pressure. The relevant questions, then, evolve not around whether to promote or transfer MSPs, but how to enhance their effectiveness and added value in fragile settings, through the transfer of knowledge. The research question that guides our analysis is: 
How applicable are MSPs in fragile contexts? How can donor organizations play a role in enhancing the effectiveness and added value of MSPs in fragile situations, if at all?

To answer this question, we first describe the MSPs and their features. This includes the characteristics of each MSP (initiation and origin, objectives, actors, activities and approach, funding); the governance of each MSP (preparation phase, decision making and implementation, information and communication, completion, continuation; and the output of each MSP (achievement of objectives and sustainability).

Second, we analyse the added value and effectiveness of MSPs in the WASH sector. Effectiveness is defined here as the achievement of the objectives as set out by the stakeholders and the sustainability of these achievements. In addition to three cases from the water sector, we include a case from the waste sector. Due to its impact on the quality of the groundwater, we consider adequate solid waste management 'part and parcel' of effective water resource management in a region that is dependent on groundwater. We refer to this combined water and waste sector as WASH+.

Third, we focus on the contextual factors affecting the governance and effectiveness of the MSPs studied. Throughout the chapter we refer to several ideas of the Contextual Interaction Theory (CIT). This is relevant since the core assumption underlying CIT (that contextual factors assert important influence over the process and effectiveness of policy implementation) corresponds well with our main arguments. We do not, however, claim to apply all components of CIT in a comprehensive way. We particularly draw on the distinction between wider, structural and casespecific contexts to address the impact of political instability (as part of the wider context) and institutional multiplicity (as part of the structural context) on MSPs. With structural context, we imply the multiplicity of governance levels, networks, perspectives, strategies and resources as envisioned by Bressers and de Boer in Chapter 3.

Two contextual factors are selected to illustrate the challenges of multistakeholder governance concepts in fragile settings: the Israeli-Palestinian conflict at large; and the fragmentation of the West Bank in areas A, B and $\mathrm{C}$ and the parallel institutions resulting from the governmental HamasFatah divide.

\subsection{Methodology}

Researchers from the Palestinian Hydrology Group (PHG), together with the authors, collected the data between 2009 and 2011 in a research project on four MSP cases in the water, sanitation and solid waste sectors. The research was part of the Peace, Security and Development Network (PSDN) initiated by the Dutch Ministry of Foreign Affairs (Stel et al., 2012). The 
qualitative methodology comprised extensive literature and secondary sources research; in-depth interviews and focus groups with a total of ninetyeight respondents; and four validation and consultation workshops with respondents and experts. ${ }^{2}$ The analysis of the MSPs was facilitated by a theoretical and analytical framework, which was developed by the consortium (Noor et al., 2010). The validation and consultation workshops that took place mid-term and at the end of the project further contributed to adequate interpretation and analysis of the data.

In the Palestinian Territories, the cases were selected on the basis of the general criteria from the PSDN. The selection criteria were that the MSP is organized around utilities such as water supply and sanitation, wastewater, and solid waste management; involves private, public and civil actors; and has a measurable output. An additional desire of local partners was to include initiatives which were of strategic importance or unique in some way. These unique features are elaborated upon in Section 9.4. Research on the case study in the Gaza Strip was hampered by impeded access to the Gaza Strip and lack of possibilities from PHG research staff in Gaza to communicate with the Head Office in Ramallah: video and Skype connections failed consistently. In the next section, we first discuss the development of MSPs as a tool in donor policy in the section below.

\subsection{The features of Palestinian MSPs}

The first case study concerns the rehabilitation of groundwater wells around two cities in the Northern West Bank: Qalqiliya and Tulkarem. Both cities are located close to the Green Line ${ }^{3}$ and the Separation Wall, the barrier built by Israel on the Palestinian side of the Green Line. The problems the MSP sought to address through the well rehabilitation included:

1 frequent interruption of water supply;

2 excessive operation costs for the wells;

3 high debts among well owners and municipalities running the wells;

4 limited well capacity; contamination by sewage water and flooding from settlements; limited pump capacity;

5 insufficient water supply to cover the needs of communities;

6 decreased agricultural productivity due to abandoned land; and

7 lack of skills among well owners and operators.

Farmers, groundwater well owners, village councils and municipalities, national governmental organizations, non-governmental organizations (NGOs), and international organizations were able to ensure good cooperation and results by substantially increasing access to water ${ }^{4}$ for domestic and agricultural use.

The second case study regards a landfill located in the Zahrat Al Finjan region approximately $17 \mathrm{~km}$ south-west of the Northern West Bank city 
Jenin. Before the establishment of the landfill, poor management of the solid waste collection and disposal services in Jenin governorate were considered to affect soil, public health, environment and water resources. The pollution created by the former unregulated waste dumps that have affected the groundwater supplies through infiltration in the soil was a great concern. This was not only an issue for the Palestinian authorities, but also for the Israeli authorities, since the surrounding Israeli settlements were extracting their water from the same source. The Zahrat Al Finjan landfill was initiated in 1998 by the World Bank under the Solid Waste and Environmental Management Project. The project aimed to implement an environmentally sound solid waste management system for the Jenin governorate, that included:

1 safe disposal of solid waste in controlled landfills;

2 environmentally sound collection and transfer of solid wastes to landfills in Jenin district;

3 stakeholder ownership of the project;

4 enhanced implementation capacity; and

5 enhanced monitoring and enforcement capacity.

The World Bank worked together with the European Community Humanitarian Office (ECHO), a number of ministries, local governmental organizations, such as the Jenin Service Council; the Project Implementation Unit and Jenin governor; Israeli authorities, and contractors. The success of this landfill project is remarkable, since the Second Intifada started almost immediately after the start of the project. Furthermore, the Israeli Civilian Administration granted approval to construct this facility while many other proposals were rejected or delayed. As a result, it is one of the few regulated and formal landfills in Palestine.

The third case study is a wastewater treatment plant located in Kharas in the southern part of West Bank, approximately eight kilometres west of Hebron City. The treatment plant project was a response to the local community that sought an alternative for sewage disposal into cesspits that polluted their groundwater as well as their drinking water supply. Local stakeholders (inhabitants, landowners, farmers, local councils) worked together with governmental organizations (both at local and national level), NGOs and international organizations. The project was among the first wastewater treatment plants implemented in the rural areas of the southern part of the West Bank. It is innovative since it collects and treats sewage at the village level, rather than at the household level. It introduced low-cost and efficient technology for sewage treatment with the objectives to improve hygienic conditions; protect water quality; reduce pollution loads; and demonstrate possibilities for sound collection and treatment of wastewater at the village level. During the first seven years, the treatment facility offered a good sanitary solution. Thereafter, the operation failed 
due to challenges in management capacity, communication and revenue collection.

The fourth case study concerns a desalination plant in the Gaza Strip's Bureij camp. This station was established after a 2006 assessment showed how much citizens in Bureij area suffered from high salinity of drinking water. The situation in Gaza is not only constrained by repeated episodes of violence and military operations and by withdrawal of donor organizations after Hamas won the elections, but also by a double public administration (one run by Hamas, the other one inactive under the Palestinian Authority). The MSP's activities included rehabilitation and upgrading of a municipal well and installation of a desalination plant; construction of a reservoir to blend the water with water from other wells; closing of two contaminated wells; and the provision of training for the operation and management of the water supply system. The PHG and the Italian Civil Group of Volunteers (Groppo Volenterinto Civile) were responsible for implementation. They worked together with Terra des Hommes Italy, a local water committee, the Palestinian Water Authority, the Municipality of Bureij, the Coastal Municipal Water Utility, and Gaza Electrical Distribution Company.

\subsection{Added value and effectiveness of the Palestinian MSPs}

In the four Palestinian MSPs studied, the MSP approach was perceived as a self-evident and inevitable way of resolving problems in the water, wastewater and waste sector, rather than as a conscious or innovative way of arranging WASH+ services. Our research suggests that MSPs exist in Palestine as an empirical reality, but have little significance as an explicit policy concept. In Palestine, MSPs are implemented on a case-by-case basis, dependent on individual donors and NGOs. Those MSPs predominantly originated as organically emerging cooperation mechanisms rather than as results of conscious policymaking:

- In case 1, the MSP in Qalqiliya and Tulkarem, a group of farmers sent applications to the village council to help them rehabilitate some of their irrigation wells. The village council contacted the PHG to assist them for the rehabilitation of these wells and the PHG subsequently wrote a proposal and submitted this to the European Union and invited farmers and well owners to discuss their problems.

- In case 2, the Zahrat Al Finjan landfill, the MSP was designed explicitly as a MSP under the World Solid Waste and Environmental Management Project. Several workshops and meetings with key experts, however, indicated that such predetermined 'MSP-ness' is not common in Palestine.

- The MSP in Kharas, case 3, also emerged without any MSP blueprint or ideology. It was a response from the PHG to local community needs. 
- The MSP in Al-Bureij, case 4, started as a partnership between the Civil Group of Volunteers and the PHG. They cooperated with local community-based organizations, the municipality, the Palestinian Water Authority (PWA), and broadened partnership with participation of semi-public entities (utilities) to achieve the objectives.

In terms of the governance and implementation of the MSPs, our cases show that MSPs can have a multi-stakeholder governance structure or practice without being officially initiated as an MSP. These MSPs are therefore the result of the specific history consisting of previous decisionmaking processes (see also Chapter 3). A history of professional cooperation and joint decision-making was found to contribute positively to the motivation of actors, to the functioning of MSPs and thereby to their effectiveness, but only when this history of cooperation was perceived as unproblematic. Such organically emerging processes are not necessarily ungoverned, anarchical or homogenous, but can arrive at much the same practices as 'official' MSPs (Warner cited in Nuijten, 2004, p. 118).

- The tasks of the main actors in case 1 had been specified pragmatically and a steering committee was eventually established (ECHO, 2010, p. 64-66). The good cooperation between stakeholders was, according to our respondents, the result of a long history of professional cooperation and an intrinsic appreciation of cooperation by beneficiaries and partners. However, the sustainability of the project could not be ensured, despite being a priority among MSP members from the start.

- Case 2 seems to be exceptional as it explicitly opted for an MSP approach from its initiation. Respondents and evaluation reports recall intensive and institutionalized communication and dialogue among all stakeholders involved throughout all phases and continuous investment in realizing both anonymity and equity of all partners in the MSP's decision-making process (World Bank, 2009). The World Bank's on-the-ground-support unit provided for effective communication with the Israeli civilian and military authorities.

- The governance context of case 3 yields a less positive picture - of problematic communal relationships and a lack of internal capacity hampering communication and effectiveness. While the governance of the MSP was characterized by multi-stakeholder interaction, it was not a smooth process. Lengthy and intensive processes of negotiation were required among and with stakeholders; between village council and landowners; between community and ministries; and between the PHG and the national governmental institutions involved (EHP, 2002).

- Due to political developments (electoral victory of Hamas) and the subsequent change of government in Gaza, the membership of stakeholder organizations in case 4 changed repeatedly. The uncertainty 
during transition has affected not only the local water committee, but also the Municipality of Al-Bureij and the replacement of staff at PWA in Gaza.

When it comes to the effectiveness and output of the MSPs studied, several observations can be made. As noted above, multi-stakeholder involvement in the governance and implementation of a project does not guarantee achievement of all objectives as was seen in cases 3 and 4. The MSP established for the Zahrat Al Finjan landfill, which was most consciously and formally conceived of as an MSP, did have the most positive and sustainable output according to respondents. Whether this was due to the formalization of cooperation within the project or other factors such as the more extensive donor commitment is hard to establish. Nonetheless, respondents were convinced that the inclusive and communicative nature of the project contributed to its success. For the other three cases MSPs in practice but not on official paper - achieving objectives in terms of 'hardware' (construction) proved significantly more feasible than improving 'software' (institutional strengthening, capacity building, awareness raising).

Considering the above, our findings are multiple - and perhaps paradoxical. On the one hand, the WASH+ initiatives we studied are functioning as MSPs even if they are not instigated as MSPs or officially presented and recognized as such. MSPs are thus an empirical reality even without being influenced by policy prescriptions. At the same time, we note that the output of the one MSP that was formally initiated and governed as an MSP (case 2) was more successful and sustainable in output terms. Although stakeholders attributed the success of this project to a range of factors, stakeholders repeatedly commended the MSP structure and governance of the Jenin Joint Service Council. Finally, for the effectiveness and outputs of the MSP, the added value of active involvement and commitment by donor organizations in MSPs is particularly recognized by stakeholders, primarily in relation to pressure on Israeli authorities for granting permits required during project implementation.

\subsection{The influence of the wider context on Palestinian WASH+ MSPs}

It is important to note that not everyone shares the widespread policy enthusiasm for MSPs in supranational policymaking networks described in Section 9.3. The 'neutral' management and government discourse in which MSPs are often cast, risks depoliticizing processes that are in fact highly political, and essentially determining 'who gets what water, when and how' (Tropp, 2005). Moreover, the difficulty of generating a common vision and action plan in conflict-affected situations is underrepresented in MSP research (Warner, 2006, p. 20). This multifaceted critique on MSPs as a 
transferable policy concept is even more relevant in so-called fragile situations.

Two core features characterize politically fragile or hybrid situations and set them apart from 'traditional' developing settings: (1) (the risk of recurrent) violent conflict and the vulnerability to external shocks related to it; and (2) politicization of public goods provision and institutional multiplicity (Naudé et al., 2011; Boege et al., 2009; Hofmann, 2009) . ${ }^{5}$ Below we explore the influence of a wider fragile context on the structural and case-specific contexts of our cases. For the Palestinian wider context, we draw attention to three concurrent attributes signifying fragility. The first contextual attribute is the Israeli-Palestinian conflict at large, related to the risk of (recurrent) violent conflict. The second is the institutional multiplicity as exemplified by the governmental divide between Fatah and Hamas in the Gaza Strip. Third, there is the administrative fragmentation in areas A, B and C in the West Bank. We therefore focus on factors that are related to the political context, and much less to the economic, cultural or technological contexts.

\section{The impact of the Israeli-Palestinian conflict on the institutional setting}

The present problems regarding water resources management in Israel and the Palestinian Territories have their roots in the Partition Plan of 1947; the unilateral declaration of the establishment of Israel in 1948; the 1967 war; the Oslo Agreements and internal developments. Israel took control over the water resources in the West Bank after the 1967 war. This was arranged through a number of Military Orders. Before the Oslo Agreements, the West Bank Water Department was the largest water distributor in the West Bank. The Interim Agreement of 1995 facilitated the transfer of responsibilities to the PWA. This transfer has resulted in an intricate and multilevel governance system characterized by the inherent (even inevitable) involvement of multiple stakeholders.

First, the PWA and the Israeli Water Authority are legally obliged to work together in the Joint Water Committee, which was established as a result of the Interim Agreement. Although Joint Water Committee decision making is officially based on consensus and both countries are formally equally represented, stakeholders perceive that the committee reiterates existing power imbalances between Israel and Palestine. ${ }^{6}$ A PWA spokesperson called it 'the unwelcome stakeholder' (Stel, 2012, p. 5).

Second, cooperation between the PWA and municipalities is institutionalized and arranged by Local Authorities Law no. 1, 1997. However, the lack of sovereignty of the Palestinian authorities, and the subsequent lack of trust in the authorities, has led to a situation in which citizens do not rely on the state to provide certain basic services. As a result, some communitybased organizations and NGOs are trying to improve the local situation with regard to water supply, sanitation and hygiene, in cooperation with local 
authorities. In this regard, various private enterprises, ranging from local truck vendors to fully fledged PPPs, fill the gap left by the public sector by responding to citizens' demands and making profit from the situation.

Third, the Palestinian WASH+ sector - as in most other developing countries - includes many national and international NGOs and donor agencies. Bilateral and multilateral donors are involved in a variety of coordination mechanisms in various sectors. International NGOs and donors that are involved in water and sanitation coordinate their efforts in the Association of International Development Agencies; the Emergency Water, Sanitation and Hygiene Group (EWASH); the Consolidated Appeal Process for the Occupied Palestinian Territories and the Organization for Coordination of Humanitarian Affairs.

The uncertainty, politicization of service delivery and institutional and practical restrictions in terms of permits, mobility and access to water resources brought about by the conflict create a greater need for actors to work together. In our case studies, we found several examples of how this context shaped the motives, cognitions and resources of the actors involved in the MSPs. Regarding case 1, the impact of wider context specifically influenced first the cognitions and subsequently the motives of local authorities. In 2003, a group of farmers from the Qalqiliya and Tulkarem area sent applications to the village council asking for urgent intervention to help them rehabilitate some of their irrigation wells to use them again for irrigation purposes. Initially, the rehabilitation of irrigation wells did not have a high priority for the village council. This changed, however, after the Separation Wall was built close to Qalqiliya and Tulkarem. ${ }^{7}$ The village council then contacted the PHG to assist them in the rehabilitation of these wells which eventually resulted in the 'Urgent Action to secure access of the population in the Occupied Palestinian Territories' project funded by ECHO.

The wider conflict context first changed local authorities' perceptions, or cognitions, of the problem at hand: from an agricultural predicament to a political emergency. While the rehabilitation of irrigation wells initially did not have a high priority for the village council, this changed after the Separation Wall was built in Qalqiliya and Tulkarem in 2002. Based on Israeli law; farmers risk losing their land if they do not cultivate it, including Palestinian farmers with land east of the Green Line. As a result, the motives of key decision-makers shifted accordingly. Interests that were initially of a practical nature (access to water, improvement of farmers' livelihoods) were now coinciding with strategic interests (continuation of cultivation of Palestinian lands between the Green Line and the Wall to maintain Palestinian land). ${ }^{8}$ This conflict-cognizant approach also manifested itself in the process of planning and implementation of the MSP in which the potential risks related to the conflict were carefully assessed and accommodated. These risks included delays in receiving permits, a 'stop of works' order by the Israeli Defence Forces and military operations. Great 
effort was taken to minimize risks that water users would be cut off from water and to obtain the resources (in this case permits) for the transfer of equipment required for rehabilitation of the wells.

Case 2 was affected by the wider conflict context as well. The start of the landfill project in October 2000 coincided with the start of the Second Intifada, which threatened to crucially undermine the available resources to initiate this ambitious project. Not surprisingly, some international staff decided to leave the country. Furthermore, the situation created great reluctance among international contractors and consultants to engage in bidding activities. The hostilities, that started in September 2000 and rapidly gained momentum between September and December, had a major impact on the project in terms of increased requirements by the Israeli authorities for constructors to apply for permits to use and transport certain types of equipment. The conflict dynamics caused delays in preparation and execution of the core landfill component due to the closing-off of Jenin by the Israeli Defence Forces and because 'project offices were shot at, waste containers and access roads were damaged, and it was difficult for project staff, consultants and the [World] Bank supervision to operate' (World Bank, 2009, p. 5). ${ }^{9}$

\section{The impact of the government divide between Hamas and Fatah}

In January 2006, Hamas won the Palestinian parliamentary elections. This resulted in political violence between Fatah and Hamas that culminated in numerous deaths. In March 2006 Hamas began setting up its government in Gaza, which was followed by international sanctions. Public service delivery was severely weakened as a result of the internal fighting, international sanctions and the lack of administrative experience among Hamas cadre. Although Fatah and Hamas formed a unity government in March 2007, Hamas took control of Gaza in June 2007, taking over government offices and replacing Fatah officials. This was followed by a blockade of goods and people by Israel and the suspension of aid by most donors (the United States, the European Union, several European countries and the Arab states). Since the establishment of a Hamas government in Gaza, a transfer of projects took place from the 'old office' under the Palestinian Authority administration to the 'new office' under Hamas administration. The subsequent political tension and lack of communication between the old and new state institutions led to an extremely challenging context for case 4. Staff members from the Environmental Quality Authority and the PHG indicated that following a temporary suspension of their salaries after Hamas took government authority, payments to the PWA-staff were resumed under the condition that they would not resume their responsibilities, nor come to the office or take data and information with them. This transition was extremely challenging for NGOs and donors that were trying to continue their work. 
The hostile and partly paralysed institutional context following from the institutional duality of the respective Fatah and Hamas administrative structures has affected, first and foremost, the cognitions of the MSP actors in the Bureij MSP that increasingly regarded the service provision project through a political (in fact conflictual) lens and the availability of resources. Communication and cooperation between both PWA and the Coastal Municipal Water Utility and the Al-Bureij municipality worsened from 2007 onwards. The Al-Bureij municipality council was replaced on 18 July 2007. Similarly, the community-based local water committee that was established in 2006 was very weak due to the internal conflict in June 2007. Therefore, a new local committee was established in 2007 that was selected from all blocks of the served area, and thus representing various views. According to one of the MSP members, nevertheless, re-establishment did not bring about smooth cooperation within the local water committee as 'the seeds of conflict were inside this committee'. Ultimately, this particular form of institutional multiplicity (or rather institutional polarization) also affected the resources available for the MSP due to withdrawal of international donors and underutilization of Fatah capacities.

\section{The impact of the fragmentation in areas $A, B$ and $C$}

The West Bank is cantonized into various areas under different governance modalities. These areas followed from the Oslo Agreements and the areas were further demarcated by the Wye and Sharm el-Sheikh Memorandums. Area A (17 per cent of the land of the West Bank) is under Palestinian control; in Area B (24 per cent) civil affairs are under Palestinian control and security issues are under joint Palestinian-Israeli control; and Area C (64 per cent) is under Israeli civil and military control. Palestinians' access to water resources is limited by restrictions inherited from the Oslo Agreements. For example, they are not permitted to drill new wells in any of these areas or to extend existing wells without an Israeli permit, which is considered quite difficult to obtain (IDRC, 2008).

Cases 1 and 2 were particularly affected by the limited Palestinian jurisdiction and control over resources stemming from this administrative division. For both the Qalqiliya and Tulkarem irrigation well rehabilitation project and the Zahrat Al Finjan landfill in Jenin, several permits were required from the Joint Water Committee and the Israeli Civilian Administration. These permits were necessary for the choice of the location (case 2), for the design (case 2), for importing equipment (both) and for building new infrastructure (case 2). Yet, due to Jenin's vicinity to Israeli settlements, the Israeli authorities also recognized the importance of adequate waste management and the prevention of pollution of groundwater that the settlements also depend upon. As a result, the Israeli Environmental authorities were reported by MSP members to be quite helpful ${ }^{10}$ and tried to advise the Palestinians on this project. 
The Joint Water Committee has reportedly asked the Palestinian authorities, on several other occasions (not related to the four cases), to cooperate with the authorities administering the Israeli settlements on the West Bank for the establishment of new, or the rehabilitation of existing water and wastewater infrastructure - as a condition for permits. The Palestinian authorities tend to refuse such demands for obvious reasons: formal cooperation with the settlement authorities is perceived as legitimizing and recognizing settlements that are illegal according to international law.

\section{The overall impact of fragility on Palestinian MSPs in the WASH+ sectors}

Fragility in Palestine, as manifested in eruptions of violent conflict and institutional multiplicity, has had a range of negative effects on the governance and output of the MSPs studied. These effects were experienced both directly (in terms of damage to the infrastructure, the economy and mobility opportunities) ${ }^{11}$ and indirectly (in terms of institutional arrangements which were the result of the Oslo Agreements and beyond). This was most apparent in case 4 in Gaza, which was never successfully implemented according to our respondents because of the political context described. Across the cases discussed, the negative effect was most apparent in the loss of resources through withdrawal of donors, underutilization of existing capacities, obstruction and delay in implementation processes and destruction of infrastructures and material. The wider fragile context also resulted in overly politicized (and often polarized) cognitions and motives regarding service provision in general and MSP cooperation in particular.

Concurrently, our interviews clearly showed that it was exactly because of the challenges and obstacles presented by conflict and institutional multiplicity that the inclusion of multiple stakeholders in WASH+ projects became a necessity and a partnership approach towards initiating and implementing such projects was regarded self-evidently desirable and was apparent in the majority of strategic motives of MSP actors. Our research also revealed that political unrest is not necessarily prohibiting or halting processes of cooperation between multiple stakeholders to improve service delivery. Case 2 for instance, the Zahrat Al Finjan project, was submitted only two weeks before the onset of the Second Intifada, and has - despite some delay - been completed and has reached far more beneficiaries (over $600,000)$ than originally intended $(200,000)$. Moreover, case 1 in Qalqiliya and Tulkarem gained momentum (and eventual success) precisely because of the strategic relevance it acquired. The wider conflict, institutional multiplicity and lack of coherence characterizing the Palestinian WASH+ section, does not then have one singular effect, but plays out differently in different case-specific contexts. While fragmentation leads to more polarized motives, more uncertain cognitions and more zero-sum resource 
allocation in general terms (cf. Chapter 3), it can bring actors together and strengthen their ability to resolve as well.

The governance and implementation of the MSPs studied showed a remarkable flexibility, an ability "not only to see the reality as a field of obstacles, but also as a terrain of potential - often unexpected-opportunities and being adaptive enough to use every "window of opportunity" to bring the ultimate purpose closer to realization' (Chapter 3 of this book). Processes of cooperation and social interaction between multiple stakeholders clearly changed during periods of armed conflict and, spurred by events such as the Second Intifada, actors applied a range of contingency and emergency planning measures with different degrees of success. The role of donors and their ground staff changed due to the tense relations between Israelis and Palestinians. A strong involvement of donors (in particular the European Union and the World Bank) during violent episodes in maintaining cordial dialogue with military authorities and pressure on the Joint Water Committee, was essential for the continuation of the activities and achievement of objectives of some MSPs.

\subsection{Conclusion: the applicability of the MSP concept in fragile contexts}

Synthesizing our above arguments, we arrive at three interrelated conclusions considering the applicability of MSPs as a tool for the governance of WASH+ projects in fragile settings.

First, partnerships including multiple stakeholders from the public and private sectors and civil society emerge in Palestine without explicit topdown policy guidance. This leads us to agree with Warner (cited in Nuijten, 2004, p. 117) that MSPs are perhaps more an empirical practice to be analysed than a policy prescription to be spread. The degree to which partnerships are consciously branded or instigated as MSPs do not seem to significantly affect the initiation, governance and implementation of MSPs (even if the MSP that was explicitly set up as an MSP did have the most extensive and sustainable output).

Second, MSPs do not emerge despite state fragility (in the wider context), but in many case exactly because of the multiplicity in actors, structures, regulations and practices (the structural context) that can be found in fragile situations. Respondents widely recognized the need to deal with flare-ups of violent conflict, competing Fatah and Hamas governments in Gaza and the administrative fragmentation of the West Bank respondents. This on-the-ground reality implies a need for:

1 national authorization of local projects;

2 Israeli permits and approval;

3 donor funding and assistance;

4 community contributions; 
$5 \quad$ NGO lobbying and management;

6 the subsequent need for communication, exchange of information; and

7 joint management and decision making.

Third, although fragility might instigate the emergence of MSPs (for instance through adding a strategic aspect to practical motives), it simultaneously hampers their effectiveness and complicates governance and cooperation processes. This occurs as cognitions become polarized and politicized and resources diminish, remain unutilized or need to be used for conciliation rather than implementation. Thus, MSPs alone do not always guarantee a smooth process or a sustainable outcome. Problematic community relationships and conflicts can stall the process, in particular when stakeholders or beneficiaries have not been sufficiently involved in the process from the start.

The above conclusions have several implications for both the study and the support of MSPs in fragile contexts. Future focus need not so much be on promoting MSPs, as they emerge quite organically in one form or another. Donor organizations in the WASH+ sector, in Palestine at least, might benefit more from research into the potential for continuity during conflict and the dealing with hostile and contradicting authorities than from guidelines on initiation and internal stakeholder management. Moreover, instead of focusing on generalizing case-specific contexts towards a one-size-fits-all model, value might lie in exploring the diverse lessons learned on the effect of wider contexts on case-specific contexts and the different responses of stakeholders to such wider political developments.

We could not agree more with Bressers and de Boer, who state in Chapter 3 that 'understanding the various impacts from various perspectives and influencing factors - particularly in the complex policy realm of water governance - is highly dependent on context', and we hope to have convincingly argued that in 'knowing "what works, where, when and how in transferring lessons in water management"' more attention needs to devoted to the fragile political contexts in which many WASH+ projects are set.

\section{Notes}

1 See O'Riordan and Stoll-Kleeman (2002) on participatory planning and deliberative democracy; Ostrom (1990) and Mayntz (1993) on self-regulating institutions and Uphoff (1996) on participatory management (Nuijten, 2004, p. 116).

2 Findings and conclusions are discussed in detail in a report (Van der Molen et al., 2011) available on the PSDN website: www.psdnetwork.nl.

3 The Green Line was agreed upon as part of the Armistice Agreements of 1949, between Israel and the countries around Israel (Egypt, Lebanon, Jordan and Syria). 
4 The project reached 30,044 beneficiaries, $243,000 \mathrm{~m}^{2}$ of land was reclaimed in area $\mathrm{C}$ and the Seam Zone; 19,505 additional $\mathrm{m}^{3}$ water available for domestic use/month; 37 per cent reduction in operational costs; 99.6 per cent reduction of water supply interruptions, increase of average abstraction capacity from $57.5 \mathrm{~m}^{3} /$ hour to $104.8 \mathrm{~m}^{3}$ /hour; pumping capacity increased by 82 per cent and 93 per cent (Van der Molen et al., 2011, p. 41).

5 It goes beyond the purpose of this study to include a more elaborate discussion of the academic debate on fragility. A comprehensive overview can be found in Van Overbeek et al. (2009).

6 See: http://siteresources.worldbank.org/INTWESTBANKGAZA/Resources/ Annex12,Aug31,2009(enriched).pdf; http://siteresources.worldbank.org/ INTWESTBANKGAZA/Resources/WaterRestrictionsReport18Apr2009.pdf; and http://go.worldbank.org/71X59QSH80, accessed 1 December 2011.

7 The high price of water contributed to the abandonment of land by 123 farmers, resulting in $570,000 \mathrm{~m}^{2}$ (570 dunums) uncultivated, of which 480 dunums in area C, and ninety dunums in the seam zone (ECHO, 2010, p. 8).

8 The project, managed by the MSP, was effective in achieving both objectives, by providing an additional $19,505 \mathrm{~m}^{3} /$ month for domestic water supply, by 37 per cent reduction of operational costs, by 99.6 per cent reduction of water supply interruptions, and by reclaiming 243 dunums of land in area $\mathrm{C}$ and in the seam zone. It was less successful in guaranteeing sustainability.

9 The damage to the solid waste infrastructure in Jenin and Tubas governorates resulting from actions by the Israeli Defence Forces in the West Bank between March and May 2002 was estimated at US\$169,820. Operation Cast Lead of December 2008/January 2009 resulted in damage of water and wastewater infrastructure in the Gaza Strip, with an estimated cost of US\$6 million (CMWU, 2009).

10 Cooperation may also have been facilitated by the Joint Services Council decision to hire an Israeli solid waste management expert for redesign of the landfill and supervision of the construction.

11 Akkaya et al. (2011) elaborately discuss the detrimental effects of the closures regime (consisting of continuous, but unannounced physical and administrative road blocks, checkpoints, barriers) on the Palestinian economy. Following Diwan and Shaban (1999) and Fischer et al.(2001) and in line with UNESCO data, Akkaya et al. estimate that each day of closure costs the Palestinian economy US\$7 million in terms of lost income.

\section{References}

Akkaya, S., Fiess, N., Kaminski, B. and G. Raballand, G. (2011) 'Fragility and conflict in Palestine: The costs of the closures regime on West Bank and Gaza', in W. Naudé, A.U. Santos-Paulino and M. McGillivray (eds) Fragile States: Causes, Costs and Responses, Oxford University Press, Oxford.

Boege, V., Brown, M. and Clements, K. (2009) 'Hybrid political orders, not fragile states', Peace Review, vol. 21, no. 1, pp. 13-21.

CMWU (Coastal Municipalities Water Utility) (2009) Damage Assessment Report 'Water and Waste Water Infrastructure and Facilities' Gaza, 27 Dec. 2008-19 Jan. 2009, online, available at: www.ochaopt.org/documents/opt_wash_cmwu_Water_ Wastewater_Infra_Damage_jan_2009.pdf, accessed 29 October 2012.

De Boer, D. and Pfisterer, S. (2009) 'The missing link in state-building: Bilateral donor and donor NGO policies on linking state-society building in fragile states', in G. Molier and E. Nieuwenhuys (eds) Peace, Security and Development in the Era of 
Globalization: The Integrated Security Approach viewed from a Multidisciplinary Perspective, Leiden University, Leiden.

DfID (Department for International Development) (2011) State-Building, PeaceBuilding and Service Delivery in Fragile and Conflict Affected States: Literature Review: Final Report, DfID, London.

Diwan, I. and Shaban, R.A. (eds) (1999) Development Under Adversity: The Palestinian Economy in Transition, 489, Palestine Economic Policy Research Institute (MAS) and the World Bank, Washington, DC.

ECHO (European Commission Directorate General for Humanitarian Aid) (2010) Single Form for Humanitarian Aid Actions: Final Report - version 14/06/2010, ECHO, Brussels.

EHP (Environmental Health Project) (2002) Village Waste Water System Feasibility Report for the West Hebron and South Nablus Clusters: Final Report, prepared for the USAID Mission for the West Bank and Gaza under Task Order HRN-1-802-99-00011-00.

Fischer, S., Alonso-Gamo, P. and Erickson von Allmen, U. (2001) 'Economic Development in the West Bank and Gaza since Oslo', The Economic Journal, vol. 111, no. 472, pp.254-275.

Grimsey, D. and Lewis, M. (2004) 'The governance of contractual relationships in public-private partnerships', The Journal of Corporate Citizenship, vol. 15, pp. 91-109

Hemmati, M. (2002) Multi-Stakeholder Processes for Governance and Sustainability. Beyond Deadlock and Conflict, Earthscan, London.

Hofmann, B. (2009) 'Are hybrid political orders an appropriate concept for state formation? Timor-Leste revisited', in Berghof Handbook Dialogue, No. 8, Berghof Research Center for Constructive Conflict Management, Berlin.

IDRC (International Development Research Centre) (2008) 'Water in Palestine', formerly available at: www.idrc.ca/en/ev-65880-201-1-DO_TOPIC.html, accessed 3 October 2008.

Mayntz, R. (1993) 'Governing failures and the problem of governability: Some comments on a theoretical paradigm', in J. Kooiman (ed.) Modern Governance: New Government-Society Interactions, Sage, London.

Multipart (2008) 'Multi-stakeholder partnership in post-conflict reconstruction: the role of EU, Theoretical \& methodological framework and guidance for the project', online, available at: www.humansecuritygateway.com/documents/ MULTIPART_MultiStakeholderPartnerships_PostConflictReconstruction_ RoleOfEU.pdf, accessed 11 February 2009.

Naudé, W., Santos-Paulino, A.U. and McGillivray, M. (eds) (2011) Fragile States. Causes, Costs and Responses, Oxford University Press, Oxford.

Noor, M. (2010) 'Multi-stakeholder processes', in M. Noor, N. Douma, G. van der Haar, D. Hilhorst, I. van der Molen and N. Stel Multi-Stakeholder Processes, Service Delivery and State Institutions. Theoretical Framework and Methodologies, Working Paper, Network for Peace, Security and Development, the Netherlands, pp.34-49, online, available at: www.psdnetwork.nl/documenten/publications/20100301_ Theoretical_Framework_\&_Methodologies_.pdf.

Noor, M., Douma, N., Van der Haar, G., Hilhorst, D., van der Molen, I. and Stel, N. (2010) Multi-Stakeholder Processes, Service Delivery and State Institutions. Theoretical Framework and Methodologies, Working Working Paper, Network for Peace, Security and Development, the Netherlands, online, available at: www.psdnetwork.nl/ 
documenten/publications/20100301_Theoretical_Framework_\&_Methodologies -.pdf.

Nuijten, M. (2004) 'Governance in action: Some theoretical and practical reflections on a key concept', in D. Kalb, W. Pansters and H. Siebers (eds) Globalization and Development: Themes and Concepts in Current Research, Kluwer Academic Publishers, New York, pp. 103-130.

OECD (Organisation for Economic Co-operation and Development) (2008) 'Service Delivery in Fragile Situations. Key concepts, findings and lessons', Journal of Development, vol. 9, no. 3, pp. 3-54.

OECD (Organisation for Economic Co-operation and Development) (2012) Meeting the Water Reform Challenge, OECD Studies on Water, OECD Publishing, Paris.

O'Riordan, T. and Stoll-Kleeman, S. (eds) (2002) Biodiversity, Sustainability and Human Communities: Protecting Beyond the protected, Cambridge University Press, Cambridge.

Ostrom, F. (1990) Governing the Commons: The Evolution of Institutions for Collective Action, Cambridge University Press, Cambridge.

Pierre, J. and Peters, G.B. (2000) Governance, Politics and the State, St. Martin's Press, New York.

Plummer, J. and Slaymaker, T. (2007) Rethinking Governance in Water Services, Working Paper 284, Overseas Development Institute, London.

Sørensen, E. and Torfing, J. (2005) 'The democratic anchoring of governance networks', Scandinavian Political Studies, vol. 28, no. 3, pp.195-218.

Stel, N.M. (2012) 'Conference report service provision and the legitimacy of state institutions in situations of conflict and fragility - The Hague, 7 December 2011', Maastricht School of Management, Maastricht, online, available at: www. psdnetwork.nl/documenten/publications/20120103_Conference_Report_ Service_Provision_and_the_Legitimacy_of_State_Institutions_in_Situations_of_ Conflict_and_Fragility.pdf.

Stel, N.M., De Boer, D. and Hilhorst, D. (2012) 'Multi-stakeholder processes, service provision and the legitimacy of state institutions in situations of conflict and fragility: Experiences from Burundi, DR Congo, Nepal and the Palestinian Territories', Synthesis Report of the working group 'MSPs, Service Delivery and State Institutions' of the Peace, Security and Development Network, online, available at: www.psdnetwork.nl/documenten/publications/20120202_Synthesis_ Report_Multi_Stakeholder_Processes_Service_Delivery_and_State_Insitutions. pdf.

Tropp, H. (2005) 'Developing water governance capacities', feature article, UNDP Water Governance Facility/SIWI, Stockholm.

United Nations Development Programme (2004) Water Governance for Poverty Reduction: Key Issues and the UNDP Response to the Millennium Development Goals, UNDP, New York.

Uphoff, N. (1996) Learning from Gal Oya, Possibilities for Participatory Development and Post-Newtonian Social Science, Intermedia Technology Publications, London.

Van der Molen, I., Hasan, W. and Tamimi, A. (2011) Multi-stakeholder Processes, Service Delivery and State Institutions: Experiences from the West Bank and Gaza Strip, Palestinian Territories, Report of the Working Group on Multi-Stakeholder Processes, Service Delivery and State Institutions of the Peace, Security and Development Network in cooperation with the Palestinian Hydrology Group. 


\section{I. van der Molen and N. Stel}

Van Overbeek, F., Hollander, T., Van der Molen, I., Willems, R., Frerks, G. and Anten, L. (2009) The Fragile States Discourse Unveiled, Working Paper 1, Peace, Security and Development Network, Utrecht.

van Tongeren, P. and van Empel, C. (eds) (2007) Joint Action for Prevention Civil Society and Government Cooperation on Conflict Prevention and Peacebuilding, Issue Paper 4, European Centre for Conflict Prevention/Global Secretariat of the Global Partnership for the Prevention of Armed Conflict.

Vermeulen, S., Woodhill, J., Proctor, F. and Delnoy, R. (2008) 'Chain-wide learning for inclusive agrifood market development: A guide to multi-stakeholder processes for linking small-scale producers to modern markets', International Institute for Environment and Development (IIED), UK and the Capacity Development and Institutional Change Program (CD\&IC), Wageningen University and Research Centre, the Netherlands.

Warner, J.F. (2006) 'More sustainable participation? Multi-stakeholder platforms for integrated catchment management', International Journal of Water Resources Development, vol. 22, no. 1, pp. 15-35.

World Bank (2009) West Bank and Gaza: Assessment of restrictions on Palestinian Water Sector Development, Sector Note, Report No. 47657-GZ, World Bank, Middle-East and North-Africa Region. 